Revisão Sistemática

Systematic Review

Luana Cristina Berwig ${ }^{1}$

Mariana Marquezan ${ }^{1}$

Jovana de Moura Milanesi ${ }^{1}$

Márlon Munhoz Montenegro²

Thiago Machado Ardenghi ${ }^{1}$

Ana Maria Toniolo da Silva ${ }^{1}$

\section{O gênero e a idade influenciam as dimensões do palato duro?} Revisão sistemática da literatura

\section{Do gender and age influence hard palate dimensions? A systematic review}

\section{Descritores}

Palato Duro

Medidas

Avaliação

Revisão

Gênero

Grupos Etários

Keywords

Palate, Hard

Measures

Evaluation

Review

Gender

Age Groups

Endereço para correspondência:

Luana Cristina Berwig

Av. Roraima, 1000, Prédio 26,

Sala 1418, Km 9, Camobi, Santa Maria

(RS), Brasil, CEP: 97105-900.

E-mail: luanaberwig@gmail.com

Recebido em: Outubro 11, 2017

\section{RESUMO}

Objetivo: Analisar a influência do gênero e da idade nas dimensões do palato duro, bem como verificar os parâmetros de referência disponíveis na literatura. Estratégia de pesquisa: Dois examinadores realizaram a pesquisa de forma independente nas bases de dados Cochrane Library, PubMed-Medline e Web of Knowledge utilizando os descritores de acordo com as regras de sintaxe de cada banco de dados. Critérios de seleção: Estudos em humanos observacionais ou experimentais, que avaliaram as dimensões do palato duro ou do arco dentário maxilar com pelo menos uma mensuração no plano transversal, vertical ou sagital em oclusões normais ou más oclusões classe I e que realizaram comparações das dimensões entre os gêneros e/ou idades. Análise de dados: Análise descritiva, seguindo subdivisões: delineamento, amostra, instrumentos de avaliação, medidas em milímetros e análise estatística. A qualidade dos estudos incluídos foi verificada através da escala "Newcastle Ottawa Quality". Resultados: Foram selecionados 18 estudos. Destes, 11 apresentaram resultados das dimensões do palato duro ou do arco dentário maxilar conforme o gênero, seis em idade e gênero e um somente em idade. Conclusão: As medidas foram maiores no gênero masculino e houve um aumento progressivo nas dimensões do nascimento até o período de dentição permanente.

\begin{abstract}
Purpose: Analyze the influence of gender and age on hard palate dimensions and verify the reference parameters available in the literature. Research strategies: Two reviewers independently performed a search at the Cochrane Library, PubMed-Medline and Web of Knowledge databases using descriptors according to the syntax rules of each database. Selection criteria: Observational or experimental human studies evaluating the dimensions of the hard palate or maxillary dental arch, with at least one transverse, vertical or sagittal plane measurement, in normal occlusions or class I malocclusions, and comparisons of the dimensions between genders and/or ages. Data analysis: Descriptive analysis with the following subdivisions: design, sample, evaluation instruments, measurements in millimeters, and statistical analysis. Quality of the included studies was verified by the Newcastle - Ottawa Quality scale. Results: Eighteen studies were selected and 11 presented results for hard palate or maxillary dental arch dimensions according to gender, six in age and gender and one in age only. Conclusion: The dimensions were larger in males and progressive increase in the measurements was observed from birth to the permanent dentition period.
\end{abstract}

Trabalho realizado no Departamento de Fonoaudiologia, Universidade Federal de Santa Maria - UFSM - Santa Maria (RS), Brasil.

${ }^{1}$ Universidade Federal de Santa Maria - UFSM - Santa Maria (RS), Brasil.

${ }^{2}$ Faculdade Especializada na área de Saúde do Rio Grande do Sul - FASURGS - Passo Fundo (RS), Brasil. Fonte de financiamento: nada a declarar.

Conflito de interesses: nada a declarar. 


\section{INTRODUÇÃO}

A avaliação miofuncional orofacial inclui a inspeção visual e subjetiva do palato duro por meio da avaliação antroposcópica. Atuais protocolos de avaliação clínica contemplam a avaliação da largura e da profundidade do palato duro ${ }^{(1,2)}$, tendo em vista a importância da morfologia das estruturas do sistema estomatognático para o correto processamento das funções deste sistema ${ }^{(3)}$.

O método de avaliação antroposcópica do palato duro, apesar de ser o mais utilizado entre os fonoaudiólogos, tem suas limitações devido à falta de parâmetros clínicos para classificar a largura e a profundidade do palato duro como normal, reduzida ou aumentada.

Pesquisas atuais na área da motricidade orofacial vêm sendo realizadas com o intuito de estudar os métodos quantitativos de avaliação que possam complementar o exame clínico miofuncional orofacial. Neste contexto, encontram-se na literatura alguns recursos para avaliação quantitativa do palato duro em pesquisas que tiverem como objetivo comparar as dimensões do palato duro entre diferentes grupos $\operatorname{clínicos}^{(4-8)}$ ou ainda comparar as avaliações qualitativas e quantitativas do palato duro ${ }^{(3,9)}$. Entretanto, para tornar o uso de tais recursos viáveis na prática clínica, é necessário conhecer os parâmetros de referências para análise quantitativa do palato duro de acordo com o gênero e idade.

Com base no exposto, justifica-se a realização desta revisão sistemática de literatura que buscou responder às seguintes questões: A idade e o gênero influenciam as dimensões do palato duro? Quais os parâmetros de referência das dimensões do palato duro?

\section{OBJETIVO}

O objetivo deste estudo foi realizar uma revisão sistemática da literatura para avaliar a influência do gênero e da idade nas dimensões do palato duro, bem como verificar os parâmetros de referência disponíveis na literatura.

\section{Estratégia de pesquisa}

Esta revisão sistemática da literatura buscou avaliar a associação entre gênero e idade com as dimensões do palato duro. Esta não é uma revisão sistemática de intervenção como descrito no Handbook Cochrane e PRISMA. Entretanto, as orientações do PRISMA foram seguidas sempre que possível.

Dois examinadores com conhecimento na área realizaram o processo de pesquisa de forma independente (LCB e MM). Foram pesquisados artigos publicados até junho de 2017 na Cochrane Library, PubMed-Medline e Web of Knowledge.

Apenas artigos na língua inglesa foram considerados. Adequações apropriadas nas palavras-chave foram realizadas para seguir as regras de sintaxe de cada banco de dados (Tabela 1).

Os dois examinadores avaliaram os títulos e resumos de todos os estudos encontrados. Resumos com informações insuficientes para permitir a tomada de decisão quanto à inclusão ou exclusão foram analisados na íntegra antes da decisão final. Artigos que apareceram em diferentes bases de dados foram considerados apenas uma vez. As diferenças encontradas entre os dois pesquisadores foram resolvidas por consenso. Os artigos selecionados foram então analisados com atenção para a avaliação da qualidade, controle do viés e para a extração de dados.

Salienta-se que foi necessário expandir a busca para os estudos que tivessem realizado medidas do arco dentário maxilar, devido à escassez de artigos que realizaram análise do palato duro. Justifica-se esta inclusão devido à estreita relação entre o palato duro e o arco dentário maxilar, já que ambos constituem o mesmo plano da maxila, apresentando semelhança em sua forma.

\section{Critérios de seleção}

Foram incluídos estudos observacionais ou experimentais realizados com humanos, que avaliaram as dimensões do palato duro ou do arco dentário maxilar com pelo menos uma mensuração no plano transversal, vertical ou sagital em oclusões normais ou más oclusões classe I de Angle e que tenham realizado comparações das dimensões entre o gênero e/ou idade.

Excluíram-se os estudos realizados com amostras com deformidades craniofaciais, fissuras de palato, síndromes, respiração oral, mordidas cruzadas, mordidas abertas e histórico de tratamento ortodôntico.

\section{Análise dos dados}

Após a leitura completa dos artigos selecionados, foram extraídos os seguintes dados: nome dos autores, ano de publicação, país onde o estudo foi realizado, delineamento, objetivo do estudo, características da amostra, instrumentos

Tabela 1. Base de dados e estratégias de buscas utilizadas

\begin{tabular}{|c|c|}
\hline Base de Dados & Descritores \\
\hline $\begin{array}{c}\text { Cochrane Library } \\
\text { http://cochrane.bvsalud.org/portal/php/index.php }\end{array}$ & $\begin{array}{l}\text { (palat* or "dental arch") and (measure* or height or depth or width or dimension) and } \\
\text { (Korkhaus or compass or caliper or cone-beam or cast) and ("age groups" or age or sex } \\
\text { or dimorphism or gender) not (deformities or airway or cleft or implant). }\end{array}$ \\
\hline $\begin{array}{c}\text { PubMed-Medline } \\
\text { http://www.ncbi.nlm.nih.gov/pubmed }\end{array}$ & $\begin{array}{c}\text { (palat* or "dental arch") and (measure* or height or depth or width or dimension) and } \\
\text { (Korkhaus or compass or caliper or cone-beam or cast) and ("age groups" or age or sex } \\
\text { or dimorphism or gender) not (deformities or airway or "Cleft Palate" or cleft or implant } \\
\text { or "mini implant" or miniscrew or thickness). Filter was checked for studies using } \\
\text { HUMANS. }\end{array}$ \\
\hline $\begin{array}{c}\text { Web of Knowledge } \\
\text { http://apps.webofknowledge.com }\end{array}$ & $\begin{array}{c}\text { (palat* or "dental arch") and (measure* or height or depth or width or dimension) and } \\
\text { (Korkhaus or compass or caliper or cone-beam or cast) and ("age groups" or age or sex } \\
\text { or dimorphism or gender) not (deformities or airway or "Cleft Palate" or cleft or implant } \\
\text { or "mini implant" or miniscrew or thickness). }\end{array}$ \\
\hline
\end{tabular}


utilizados para mensuração do palato duro ou do arco dentário maxilar, descrição das medidas realizadas, média das medidas de acordo com o gênero e/ou idade e o valor da significância (valor de p) quando disponível.

A avaliação da qualidade e do risco de viés dos estudos incluídos foi realizada por meio da escala "Newcastle - Ottawa Quality" elaborada em sua versão original para estudos de coorte ${ }^{(10)}$, sendo posteriormente adaptada para estudos transversais ${ }^{(11)}$. Na escala, a pontuação é atribuída em número de estrelas compreendendo três domínios: seleção, comparabilidade e desfecho/resultado. A pontuação máxima pode ser de nove pontos para estudos de coorte e dez pontos para estudos transversais. Quanto maior a pontuação atingida, maior a qualidade interna e menor o risco de viés do estudo.

\section{RESULTADOS}

O fluxograma apresenta o resultado das buscas realizadas (Figura 1). Foram encontrados 215 na base de dados Web of Knowledge, 114 artigos na Pubmed-Medline e 39 na Cochrane Library. De acordo com os critérios de seleção, 46 estudos foram selecionados de acordo com o título e resumo, dos quais cinco foram excluídos por serem duplicados. Após a leitura dos artigos na íntegra, 28 foram excluídos por não contemplarem os critérios de seleção, sendo incluídos 18 estudos.

$\mathrm{Na}$ fase de extração dos dados dos 18 estudos incluídos nesta revisão sistemática, verificou-se variabilidade nos tipos de medidas realizadas e nos pontos de referência utilizados para sua obtenção. Em vista disso, optou-se por extrair as medidas

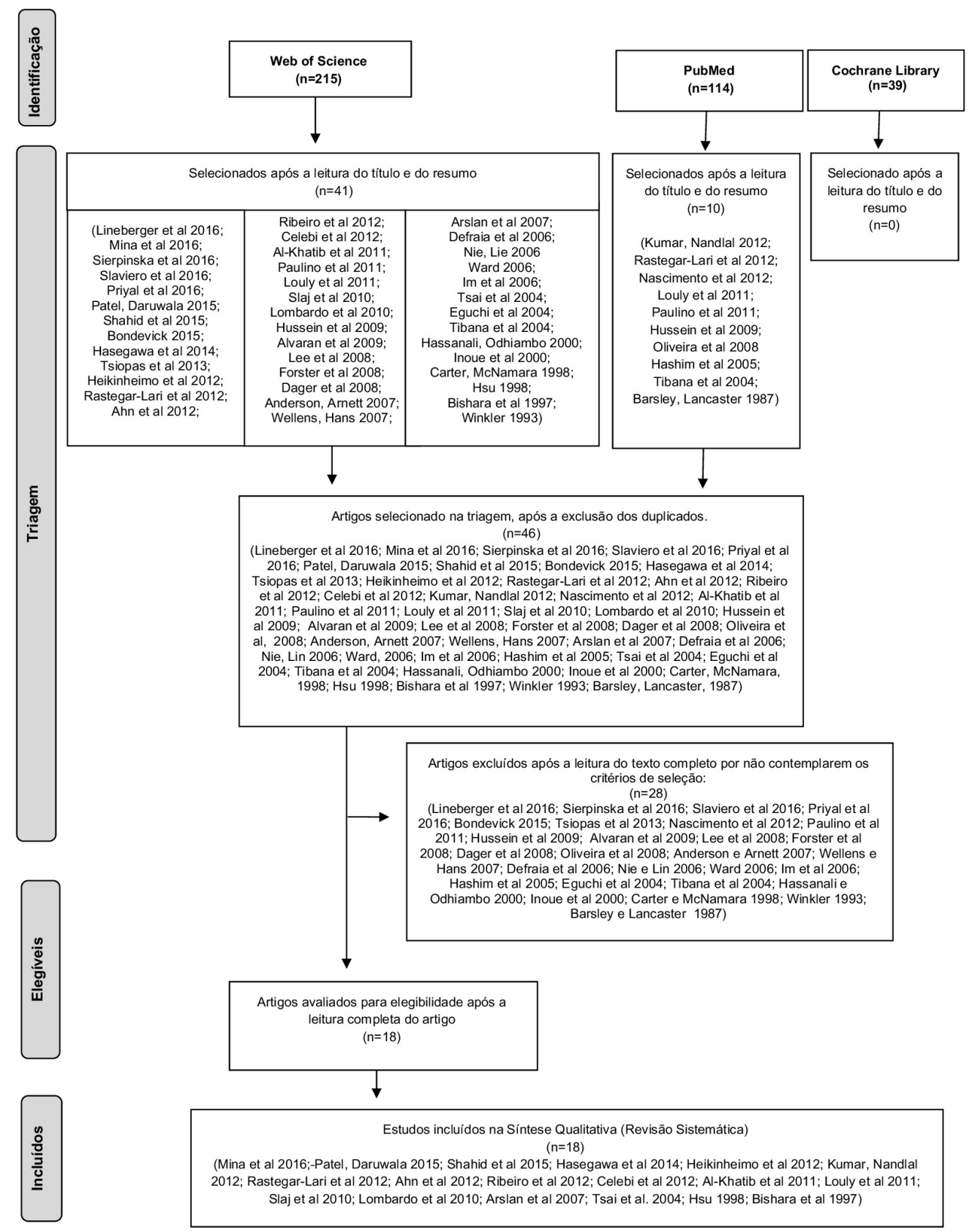

Figura 1. Fluxograma da pesquisa realizada 
relacionadas aos planos transversal, vertical e sagital, que são as de maior interesse para a Fonoaudiologia.

Para uma adequada apresentação da síntese dos resultados dos 18 estudos na Tabela 2, foi necessário uniformizar as denominações das medidas e a respectiva abreviatura com menção ao ponto de referência utilizado (Quadro 1). Quando os pontos de referência utilizados para mensuração foram marcados na gengiva, foram considerados dimensões do palato duro e, quando os pontos de referência foram marcados nos dentes (cúspides, sulcos ou fossas), foram considerados como dimensões do arco dentário maxilar.

A uniformização das denominações das medidas do palato duro no Quadro 1 foi realizada devido à falta de padronização no emprego das nomenclaturas das medidas realizadas nos

Tabela 2. Estudos que compararam as dimensões do palato duro ou do arco dental maxilar entre gênero e/ou idade

\begin{tabular}{|c|c|c|c|c|c|}
\hline Autor, ano, país & Amostra & Instrumentos & $\begin{array}{c}\text { Mensurações no } \\
\text { Gênero M milímetros } \\
(\mathrm{mm})\end{array}$ & $\begin{array}{c}\text { Mensurações no } \\
\text { Gênero F milímetros } \\
(\mathrm{mm})\end{array}$ & $\begin{array}{l}\text { Análise } \\
\text { estatística }\end{array}$ \\
\hline \multirow{4}{*}{$\begin{array}{l}\text { Mina et al. }{ }^{(12)} \\
\text { Iran }\end{array}$} & 54 sujeitos & \multirow{2}{*}{ Modelo digitalizado: } & \multirow{2}{*}{ La.1M.sv=58,9 } & \multirow{2}{*}{ La. $1 \mathrm{M} . \mathrm{sv}=57,0$} & \multirow{4}{*}{$\begin{array}{l}\text { N.S. Entre } \\
\text { gênero }\end{array}$} \\
\hline & $M=25 F=29$ & & & & \\
\hline & 12 a 16 anos & -Medidas na imagem 3D & \multirow{2}{*}{ Co. $1 \mathrm{M}=32,42$} & \multirow{2}{*}{ Co. $1 \mathrm{M}=30,82$} & \\
\hline & Md. de idade: 14 anos & com software & & & \\
\hline \multirow{4}{*}{$\begin{array}{c}\text { Patel e Daruwala }{ }^{(13)} \\
\text { Índia }\end{array}$} & 60 sujeitos & Modelo digitalizado: & La.C.cus $=34,97^{\mathrm{a}}$ & La.C.cus $=33,14^{a}$ & \multirow{4}{*}{$\begin{array}{l}\text { Letras iguais: } \\
\text { diferença entre } \\
\text { gênero }\end{array}$} \\
\hline & $M=30 F=30$ & $\begin{array}{c}\text {-Medidas na imagem 3D } \\
\text { com software }\end{array}$ & La. $2 M . c d v=58,84^{b}$ & La. $2 M . c d v=55,99^{b}$ & \\
\hline & 18 a 25 anos & & Co. $C=8,47^{c}$ & Co.C $=7,86^{c}$ & \\
\hline & & & Co. $2 M=42,54^{d}$ & Co. $2 \mathrm{M}=40,87^{\mathrm{d}}$ & \\
\hline \multirow{10}{*}{$\begin{array}{l}\text { Shahid et al. }{ }^{(14)} \\
\text { Paquistão }\end{array}$} & 128 sujeitos & Modelo de gesso: & Paquímetro digital: & Paquímetro digital: & \multirow{10}{*}{$\begin{array}{c}\text { Letras iguais: } \\
\text { diferença entre } \\
\text { gênero }\end{array}$} \\
\hline & 18 a 24 anos & -Paquímetro digital & La.C.cus $=35,99^{a}$ & La.C.cus $=34,24^{\mathrm{a}}$ & \\
\hline & & Modelo digitalizado: & La.1PM.cv=43,37b & La.1PM.cv=41,99b & \\
\hline & & -Técnica SM & La.2PM.cv $=48,97^{c}$ & La.2PM.cv=47,04c & \\
\hline & & & La. $1 \mathrm{M} . \mathrm{cmv}=53,97^{\mathrm{d}}$ & La. $1 \mathrm{M} . \mathrm{cmv}=52,16^{\mathrm{d}}$ & \\
\hline & & & Técnica SM: & Técnica SM: & \\
\hline & & & La.C.cus $=35,99^{\mathrm{e}}$ & La.C.cus $=34,26^{\mathrm{e}}$ & \\
\hline & & & La.1PM.cv $=43,37^{f}$ & La.1PM.cv=42,00 & \\
\hline & & & La.2PM.cv=48,979 & La.2PM.cv=47,049 & \\
\hline & & & La. 1 M.cmv=53,97 & La. $1 \mathrm{M} . \mathrm{cmv}=52,15^{\mathrm{h}}$ & \\
\hline \multirow{16}{*}{$\begin{array}{l}\text { Hasegawa et al. }{ }^{(15)} \\
\text { Japão }\end{array}$} & 100 sujeitos da Mongólia: & Modelo de gesso: & Mongolianos: & Mongolianos: & \multirow{16}{*}{$\begin{array}{c}\text { Letras iguais: } \\
\text { diferença entre } \\
\text { gênero }\end{array}$} \\
\hline & $\mathrm{M}=50 \mathrm{~F}=50$ & -Paquímetro digital & La.C.g $=26,37^{a}$ & La.C.g $=25,37^{a}$ & \\
\hline & Md de idade: & & La.1PM.g=30,97b & La.1PM.g=29,55 & \\
\hline & 20,8 anos & & La.1M.g=40,69c & La. $1 \mathrm{M} . \mathrm{g}=38,32^{\mathrm{c}}$ & \\
\hline & 100 sujeitos do Japão & & La. $1 \mathrm{M} . \mathrm{fc}=51,58^{\mathrm{d}}$ & La. $1 \mathrm{M} . \mathrm{fc}=49,11^{\mathrm{d}}$ & \\
\hline & $\mathrm{M}=50 \mathrm{~F}=50$ & & Co. $1 \mathrm{M}=32,32$ & Co. $1 \mathrm{M}=31,93$ & \\
\hline & Md de idade: & & CoB. $1 \mathrm{M}=32,80^{\mathrm{e}}$ & CoB. $1 \mathrm{M}=34,73^{\mathrm{e}}$ & \\
\hline & 20 anos & & $\mathrm{LaB} .1 \mathrm{PM}=49,35^{f}$ & LaB.1PM $=47,47^{f}$ & \\
\hline & & & Japoneses: & Japoneses: & \\
\hline & & & La.C.g $=26,45^{g}$ & La.C.g $=22,96^{g}$ & \\
\hline & & & La.1PM.g=30,12 ${ }^{\mathrm{h}}$ & La.1PM.g=27,38 & \\
\hline & & & La.1M.g =38,68 & La1M.g=35,57i & \\
\hline & & & La. $1 \mathrm{M} . \mathrm{fc}=49,85^{\mathrm{j}}$ & La. $1 \mathrm{M} . \mathrm{fc}=43,54^{\mathrm{j}}$ & \\
\hline & & & Co. $1 \mathrm{M}=33,97^{1}$ & $\mathrm{Co} .1 \mathrm{M}=30,28^{\prime}$ & \\
\hline & & & CoB. $1 \mathrm{PM}=30,82$ & CoB.1PM=31,32 & \\
\hline & & & LaB.1PM: 46,52m & LaB.1PM=40,41 & \\
\hline \multirow{14}{*}{$\begin{array}{l}\text { Ahn et al. }{ }^{(16)} \\
\text { Coreia do Sul }\end{array}$} & 66 sujeitos & Modelo digitalizado: & La.c.cus: & La.c.Cus: & \multirow{14}{*}{$\begin{array}{l}\text { Letras iguais: } \\
\text { diferença } \\
\text { entre gênero }\end{array}$} \\
\hline & $M=16 \quad F=50$ & $\begin{array}{c}\text {-Medidas na imagem 3D } \\
\text { com software }\end{array}$ & 6 anos $=32,33$ & 6 anos $=32,11$ & \\
\hline & 6 aos 14 anos & & 8 anos $=34,33$ & 8 anos $=33,97$ & \\
\hline & & & 9 anos $=32,92$ & 9 anos $=33,69$ & \\
\hline & & & 10 anos $=33,77$ & 10 anos $=35,14$ & \\
\hline & & & 11 anos $=33,53$ & & \\
\hline & & & La.C.cus: & La.C.cus: & \\
\hline & & & & 8 anos $=34,30$ & \\
\hline & & & 9 anos $=39,58$ & 9 anos $=35,14$ & \\
\hline & & & 10 anos $=38,36^{a}$ & 10 anos $=35,78^{a}$ & \\
\hline & & & 11 anos $=37,45$ & 11 anos $=35,85$ & \\
\hline & & & 12 anos $=37,30^{b}$ & 12 anos $=35,75^{b}$ & \\
\hline & & & 13 anos $=37,24^{c}$ & 13 anos $=35,70^{c}$ & \\
\hline & & & 14 anos $=37,15^{d}$ & 14 anos $=35,58^{d}$ & \\
\hline
\end{tabular}

Legenda: $\mathrm{M}=$ =gênero masculino; $\mathrm{F}=$ gênero feminino; $\mathrm{Md}=$ édia; $3 \mathrm{D}=$ tridimensional; $2 \mathrm{D}=$ bidimensional; $\mathrm{NS}=$ não significativo 
Tabela 2. Continuação...

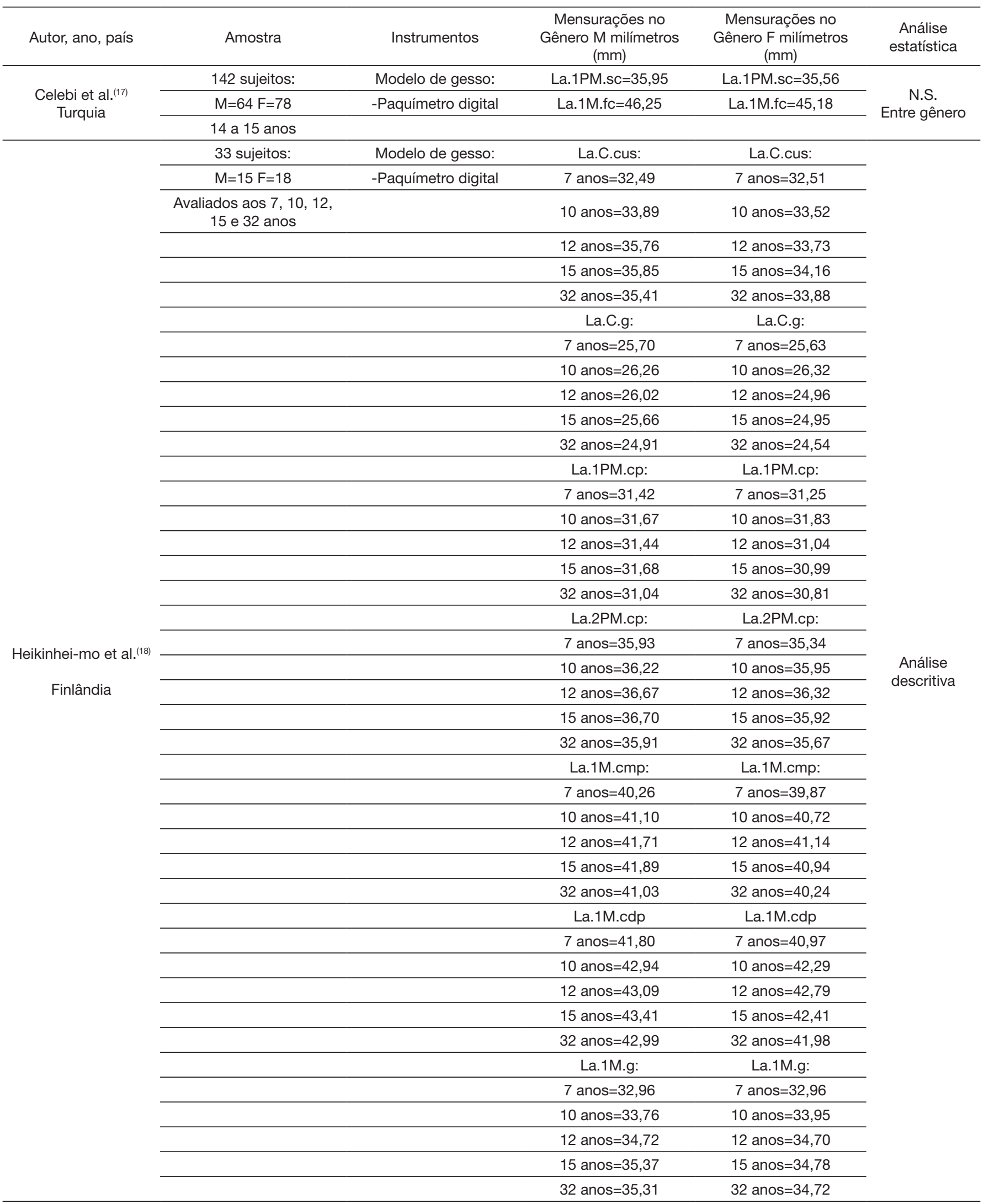

\footnotetext{
Legenda: $\mathrm{M}=$ =gênero masculino; $\mathrm{F}=$ gênero feminino; $\mathrm{Md}=$ édia; $3 \mathrm{D}=$ tridimensional; $2 \mathrm{D}=$ =bidimensional; $\mathrm{NS}=$ não significativo
} 
Tabela 2. Continuação...

\begin{tabular}{|c|c|c|c|c|c|}
\hline Autor, ano, país & Amostra & Instrumentos & $\begin{array}{c}\text { Mensurações no } \\
\text { Gênero M milímetros } \\
(\mathrm{mm})\end{array}$ & $\begin{array}{c}\text { Mensurações no } \\
\text { Gênero F milímetros } \\
(\mathrm{mm})\end{array}$ & $\begin{array}{l}\text { Análise } \\
\text { estatística }\end{array}$ \\
\hline \multirow{7}{*}{$\begin{array}{c}\text { Kumar e Nandlal(19) } \\
\text { Índia }\end{array}$} & $\begin{array}{l}\text { Grupo controle: } \\
44 \text { sujeitos }\end{array}$ & Modelo de gesso: & La.1M.cmv & La.1M.cmv & \multirow{7}{*}{$\begin{array}{l}\text { Análise } \\
\text { descritiva }\end{array}$} \\
\hline & $M=24$ & -Paquímetro digital & $6-8$ anos $=48,15$ & $6-8$ anos $=46,40$ & \\
\hline & $\begin{array}{l}-10 \text { sujeitos de } \\
6 \text { a } 8 \text { anos }\end{array}$ & $\begin{array}{l}\text {-Paquímetro analógico } \\
\text { com acessório para } \\
\text { medir a altura palatina } \\
\text { (palatal depth gauge) }\end{array}$ & $10-12$ anos $=51,21$ & $10-12$ anos $=52,89$ & \\
\hline & $\begin{array}{c}-14 \text { sujeitos de } \\
10 \text { a } 12 \text { anos } \\
\end{array}$ & & Co.1M & Co.1M & \\
\hline & $\mathrm{F}=20$ & & $6-8$ anos $=26,18$ & $6-8$ anos $=24,40$ & \\
\hline & - 7 sujeitos de 6 a 8 anos. & & $10-12$ anos $=30,89$ & $10-12$ anos $=30,77$ & \\
\hline & $\begin{array}{l}-13 \text { sujeitos de } \\
10 \text { a } 12 \text { anos } \\
\end{array}$ & & Pr.1M & Pr.1M & \\
\hline \multirow{5}{*}{$\begin{array}{c}\text { Rastegar-Lari et al. }{ }^{(20)} \\
\text { Kuwait }\end{array}$} & $\mathrm{M}=69 \mathrm{~F}=74$ & -Paquímetro digital & La.1PM.sd=38,4 & La.1PM.sd=36,63 & \multirow{5}{*}{$\begin{array}{l}\text { Letras iguais: } \\
\text { diferença entre } \\
\text { gênero }\end{array}$} \\
\hline & 13 a 14 anos & & La. $1 \mathrm{M} . \mathrm{cmv}=52,39$ & La. $1 \mathrm{M} . \mathrm{cmv}=50,31$ & \\
\hline & & & La. $1 \mathrm{M} . \mathrm{fC}=48,44$ & La. $1 \mathrm{M} . \mathrm{fc}=46,11$ & \\
\hline & & & La. $1 \mathrm{M} . \mathrm{g}=36,08$ & La.1M.g=34,95 & \\
\hline & & & Co.1PM=28,43a & Co.1PM=27,45a & \\
\hline \multirow{5}{*}{$\begin{array}{l}\text { Ribeiro et al. }{ }^{(21)} \\
\text { Brasil }\end{array}$} & 19 sujeitos: & Modelo digitalizado: & \multicolumn{2}{|c|}{ Não realizou comparação entre os gêneros } & \multirow{5}{*}{$\begin{array}{c}\text { Letras iguais: } \\
\text { diferença } \\
\text { significativa } \\
\text { entre o Tempo } \\
1 \text { e Tempo } 2\end{array}$} \\
\hline & $M=7 F=12$ & $\begin{array}{l}\text {-Medidas na imagem 3D } \\
\text { com software }\end{array}$ & \multicolumn{2}{|c|}{ La.C.cus: } & \\
\hline & Tempo 1: & & Tempo & $30,94^{a}$ & \\
\hline & 6 a 8,6 anos & & Tempo & $34,15^{\mathrm{a}}$ & \\
\hline & Tempo 2: & & La. & fc: & \\
\hline \multirow{17}{*}{$\begin{array}{l}\text { Al-Khatib et al. } \\
\text { Malásia }\end{array}$} & 3 faixas etárias: & & $15-17$ anos $=35,4$ & $15-17$ anos $=34,3$ & \\
\hline & 13-14 anos & & $\begin{array}{c}\text { 18-30 anos }=35,2 \\
\text { La.1PM.cv }\end{array}$ & $\begin{array}{c}\text { 18-30 anos }=34,1 \\
\text { La.1PM.cv }\end{array}$ & \\
\hline & $15-17$ anos & & $13-14$ anos $=42,9$ & $13-14$ anos $=41,6$ & \\
\hline & $18-30$ anos & & $15-17$ anos $=43,4$ & $15-17$ anos $=42,3$ & \\
\hline & & & $18-30$ anos $=43,6$ & $18-30$ anos $=42,0$ & \\
\hline & & & La.2PM.cv & La.2PM.cv & \\
\hline & & & $13-14$ anos $=49,4$ & $13-14$ anos $=47,0$ & \\
\hline & & & $15-17$ anos $=49,7$ & $15-17$ anos $=47,6$ & \\
\hline & & & $18-30$ anos $=49,1$ & $18-30$ anos $=47,1$ & \\
\hline & & & La.1M.cmv & La.1M.cmv & \\
\hline & & & $13-14$ anos $=54,1$ & $13-14$ anos $=51,5$ & \\
\hline & & & $15-17$ anos $=54,8$ & $15-17$ anos $=52,4$ & \\
\hline & & & $18-30$ anos $=54,3$ & $18-30$ anos $=51,9$ & \\
\hline & & & La.C.cus $=35,30^{\mathrm{a}}$ & La.C.cus $=34,10^{\mathrm{a}}$ & \\
\hline & & & La.1PM.cv=43,30 & La.1PM.cv $=42,00^{b}$ & \\
\hline & & & La.2PM.cv $=49,4^{c}$ & La.2PM.cv $=47,2^{\mathrm{c}}$ & \\
\hline & & & La. $1 \mathrm{M} . \mathrm{cmv}=54,4^{\mathrm{d}}$ & La. $1 \mathrm{M} . \mathrm{cmv}=51,9^{\mathrm{d}}$ & \\
\hline
\end{tabular}

Legenda: $\mathrm{M}=$ =gênero masculino; $\mathrm{F}=$ gênero feminino; $\mathrm{Md}=$ =média; $3 \mathrm{D}=$ =tridimensional; $2 \mathrm{D}=$ bidimensional; $\mathrm{NS}=$ não significativo 
Tabela 2. Continuação...

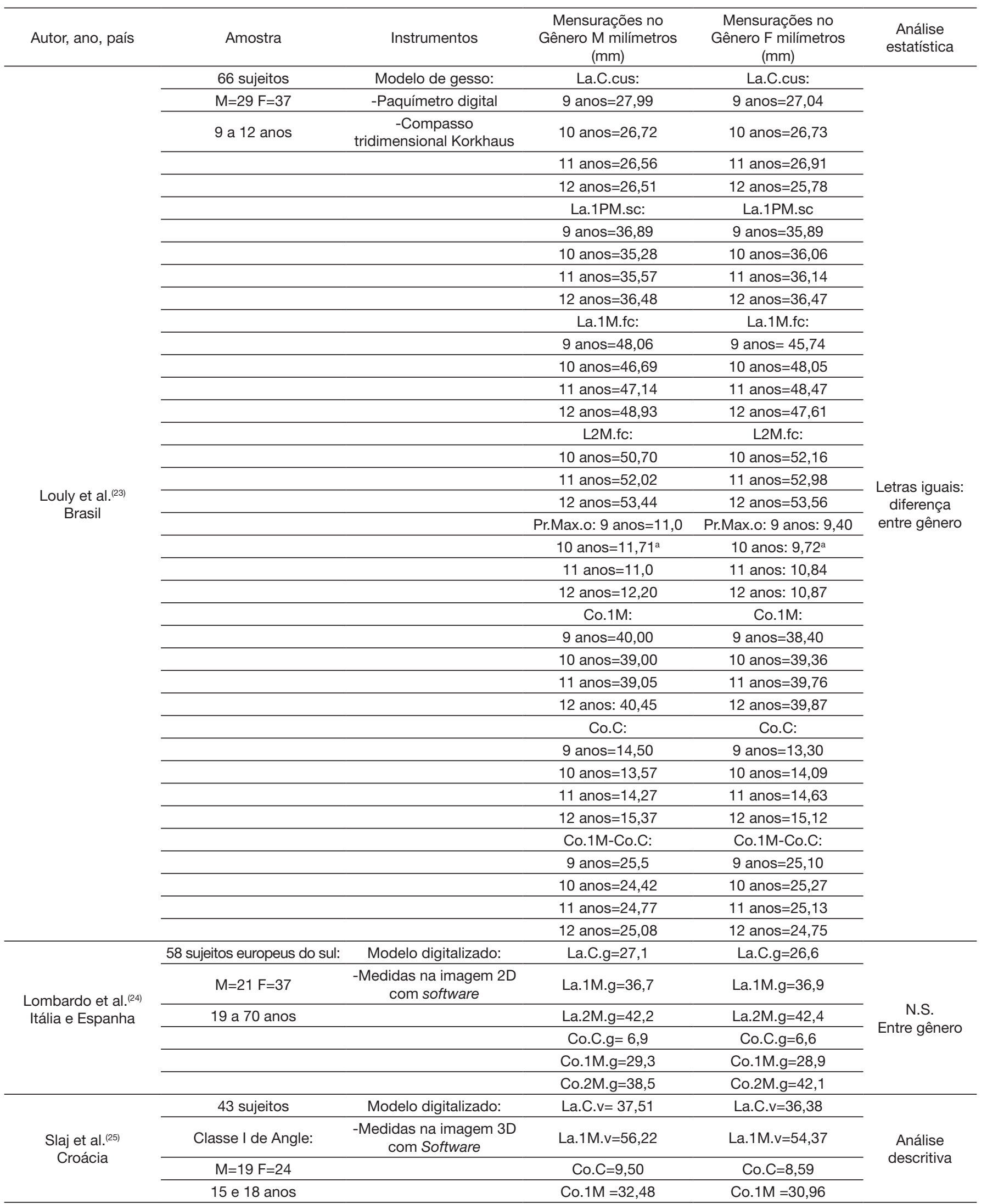

Legenda: $\mathrm{M}=$ =gênero masculino; $\mathrm{F}=$ gênero feminino; $\mathrm{Md}=$ éédia; $3 \mathrm{D}=$ =tridimensional; 2D=bidimensional; $\mathrm{NS}=$ não significativo 
Tabela 2. Continuação...

\begin{tabular}{|c|c|c|c|c|c|}
\hline Autor, ano, país & Amostra & Instrumentos & $\begin{array}{c}\text { Mensurações no } \\
\text { Gênero M milímetros } \\
(\mathrm{mm})\end{array}$ & $\begin{array}{l}\text { Mensurações no } \\
\text { Gênero F milímetros } \\
(\mathrm{mm})\end{array}$ & $\begin{array}{l}\text { Análise } \\
\text { estatística }\end{array}$ \\
\hline \multirow{3}{*}{$\begin{array}{l}\text { Arslan et al. } \\
\text { Turquia }\end{array}$} & 65 sujeitos & Modelo de gesso: & La.C.cus $=31,97$ & La.C.cus $=31,29$ & \multirow{3}{*}{$\begin{array}{c}\text { Letras iguais: } \\
\text { diferença } \\
\text { entre gênero }\end{array}$} \\
\hline & Md de idade: & & La. $1 \mathrm{M} . \mathrm{fC}=45,84^{\mathrm{b}}$ & La. $1 \mathrm{M} . \mathrm{fc}=44,15^{\mathrm{b}}$ & \\
\hline & $\mathrm{M}=9,44$ anos & & Co. $1 \mathrm{M}=28,16$ & Co. $1 \mathrm{M}=26,88$ & \\
\hline \multirow{3}{*}{$\begin{array}{l}\text { Tsai e } \operatorname{Tan}^{(27)} \\
\text { China }\end{array}$} & $\mathrm{M}=78 \mathrm{~F}=72$ & Foto do modelo: & La. $2 m \cdot g . E=15,42^{b}$ & La.2m.g.E $=14,68^{b}$ & \multirow{3}{*}{$\begin{array}{c}\text { Letras iguais: } \\
\text { diferença } \\
\text { entre gênero }\end{array}$} \\
\hline & 4 a 5 anos & \multirow{2}{*}{$\begin{array}{l}\text { - Medidas realizadas } \\
\text { com Software }\end{array}$} & Pr.2m.g=10,77 & Pr.2m.g=10,67 & \\
\hline & & & La. $2 m . c m p=34,73^{c}$ & La. $2 m . c m p=33,18^{c}$ & \\
\hline \multirow{6}{*}{$\begin{array}{l}\mathrm{Hsu}^{(28)} \\
\text { Taiwan }\end{array}$} & Grupo controle & $\begin{array}{c}\text { Largura: } \\
\text { Imagem da face oclusal } \\
\text { do modelo copiada e } \\
\text { impressa }\end{array}$ & La. $1 \mathrm{M} . \mathrm{fc}=49,81$ & La. $1 \mathrm{M} . \mathrm{fc}=48,73$ & \multirow{6}{*}{$\begin{array}{l}\text { Análise } \\
\text { descritiva }\end{array}$} \\
\hline & 12,8 a 18,3 anos & $\begin{array}{l}\text { - Medidas em folhas } \\
\text { impressas com } \\
\text { paquímetro digital }\end{array}$ & Pr. $1 \mathrm{M} . \mathrm{fc}=20,66$ & Pr.1M.fc $=20,99$ & \\
\hline & (Md. 14,3) & & & & \\
\hline & $\mathrm{F}=30$ & & & & \\
\hline & 12,9 a 19,1 anos & & & & \\
\hline & (Md.14,4) & & & & \\
\hline \multirow{19}{*}{$\begin{array}{l}\text { Bishara et al. (29) } \\
\text { Estados Unidos }\end{array}$} & Dois grupos: & Modelos dentários: & La.anterior,g: & La.anterior.g: & Letras iguais: \\
\hline & 3 a 45 anos & & La.posterior.g: & La.posterior.g: & \\
\hline & $M=15 F=15$ & & 6 semanas: $27,4^{c}$ & 6 semanas $=26,9^{n}$ & \\
\hline & $\begin{array}{l}\text { Avaliações aos } 3,5,8,13, \\
26 \text { e } 45 \text { anos }\end{array}$ & & 1 anos $=30,1^{c, d}$ & 1 ano $=29,1^{\mathrm{n}, \mathrm{o}}$ & \\
\hline & & & 2 anos $=32,7^{d}$ & 2 anos $=30,8^{\circ}$ & \\
\hline & & & La.c.cus ou La.C.cus: & La.c.cus ou La.C.cus: & \\
\hline & & & 3 anos $=28,8^{e}$ & 3 anos $=27,4^{p}$ & \\
\hline & & & 5 anos $=30,3^{e, f}$ & 5 anos $=28,4^{p, q}$ & \\
\hline & & & 8 anos $=32,5^{f, g}$ & 8 anos $=30,7^{q, r}$ & \\
\hline & & & 13 anos $=35,1^{9}$ & 13 anos $=33,1^{r}$ & \\
\hline & & & 26 anos $=34,0$ & 26 anos $=32,3^{s}$ & \\
\hline & & & 45 anos $=33,7$ & 45 anos $=31,9^{\mathrm{s}}$ & \\
\hline & & & $\begin{array}{l}\text { La. } 2 m . c m v \text { ou } \\
\text { La.1M.cmv: }\end{array}$ & $\begin{array}{l}\text { La. } 2 m . c m v \text { ou } \\
\text { La.1M.cmv: }\end{array}$ & \\
\hline & & & 3 anos $=40,9^{h}$ & 3 anos $=39,3^{t}$ & \\
\hline & & & 5 anos $=43,5^{\mathrm{h}, \mathrm{i}}$ & 5 anos $=40,8^{\mathrm{t}, \mathrm{u}}$ & \\
\hline & & & 8 anos $=51,0^{i, j}$ & 8 anos $=48,1^{u, v}$ & \\
\hline & & & 13 anos $=53,4^{j}$ & 13 anos $=50,1^{v, x}$ & \\
\hline & & & 26 anos $=53,6$ & 26 anos $=48,3^{x}$ & \\
\hline & & & 45 anos $=53,4$ & 45 anos $=48,4$ & \\
\hline
\end{tabular}


Quadro 1. Descrição das mensurações realizadas nos artigos, uniformização da nomenclatura e abreviação para extração dos dados

\begin{tabular}{|c|c|c|}
\hline $\begin{array}{l}\text { Autor } \\
\text { ano }\end{array}$ & $\begin{array}{l}\text { Descrição das mensurações realizadas no arco dentário } \\
\text { maxilar conforme os artigos selecionados }\end{array}$ & $\begin{array}{c}\text { Nomenclatura padronizada e abreviações } \\
\text { utilizadas nesta Revisão }\end{array}$ \\
\hline 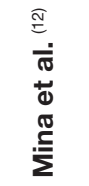 & $\begin{array}{l}\text { 1. Largura intermolar: distância entre os sulcos vestibulares dos } \\
1^{\circ} \text { molares permanentes. } \\
\text { 2. Profundida molar: distância entre o ponto de contato } \\
\text { dos incisivos centrais e a linha que conecta os } 1^{\circ} \text { molares } \\
\text { permanentes. }\end{array}$ & $\begin{array}{l}\text { 1. Largura } 1^{\circ} \text { molar maxilar entre os sulcos vestibulares (La.1M.sv). } \\
\text { 2. Comprimento } 1^{\circ} \text { molar: Co. } 1 \mathrm{M} \text {. }\end{array}$ \\
\hline 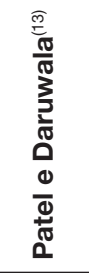 & $\begin{array}{l}\text { 1. Largura intercanina: distância entre as cúspides dos caninos. } \\
\text { 2. Largura inter } 2^{\circ} \text { molar: distância entre as cúspides } \\
\text { distovestibulares dos } 2^{\circ s} \text { molares. } \\
\text { 3. Profundidade canina: distância entre o ponto de contato dos } \\
\text { incisivos centrais e a linha que conecta as cúspides dos caninos. } \\
\text { 4. Profundida } 2^{\circ} \text { molar: distância entre o ponto de contato } \\
\text { dos incisivos centrais e a linha que conecta as cúspides } \\
\text { distovestibulares dos } 2^{\circ s} \text { molares. }\end{array}$ & $\begin{array}{l}\text { 1. Largura canina maxilar entre as cúspides (La.C.cus). } \\
\text { 2. Largura } 2^{\circ} \text { molar maxilar entre as cúspides distovestibulares } \\
\text { (La.2M.cdv). } \\
\text { 3. Comprimento canino maxilar (Co.C). } \\
\text { 4. Comprimento } 2^{\circ} \text { molar maxilar (Co.2M). }\end{array}$ \\
\hline 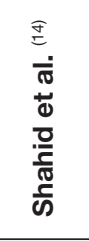 & 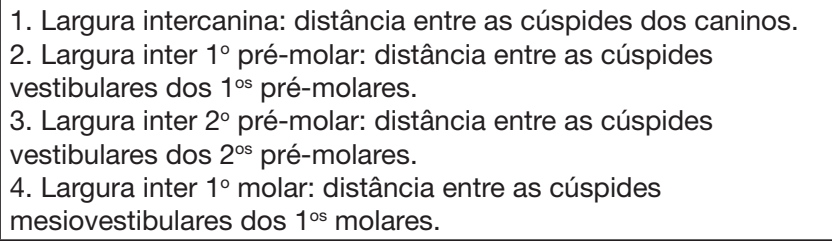 & $\begin{array}{l}\text { 1. Largura canina maxilar entre as cúspides (La.C.cus). } \\
\text { 2. Largura } 1^{\circ} \text { pré-molar maxilar entre as cúspides vestibulares } \\
\text { (La.1PM.cv). } \\
\text { 3. Largura } 2^{\circ} \text { pré-molar maxilar entre as cúspides vestibulares } \\
\text { (La.2PM.cv). } \\
\text { 4. Largura } 1^{\circ} \text { molar maxilar entre as cúspides mesiovestibulares } \\
\text { (La.1M.cmv). }\end{array}$ \\
\hline 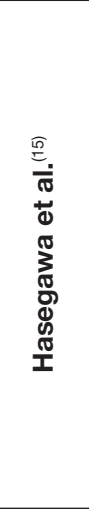 & $\begin{array}{l}\text { 1. Intercanino lingual: distância entre os caninos na interseção da } \\
\text { margem gengival e o longo eixo do dente. } \\
\text { 2. Interpremolar lingual: distância entre os } 1^{\text {os }} \text { pré-molares na } \\
\text { interseção da margem gengival e o longo eixo do dente. } \\
\text { 3. Intermolar lingual: distância entre os } 1^{\text {os }} \text { molares no nível } \\
\text { gengival do sulco lingual. } \\
\text { 4. Intermolar central: distância entre as fossas centrais dos } 1^{\text {os }} \\
\text { molares. } \\
\text { 5. Comprimento do arco coronal: medida entre o ponto mais } \\
\text { anterior da gengiva na área de contato mesial dos incisivos } \\
\text { centrais e o ponto mais distal dos } 1^{\text {os }} \text { molares. } \\
\text { 6. Comprimento do arco basal: medida entre o ponto distal dos } \\
\text { 1os molares e o ponto mais anterior do arco basal. }_{\text {7. Largura do arco basal: medida entre o ponto mais côncavo do }} \\
\text { osso basal na área dos } 1^{\text {os }} \text { pré-molares. }\end{array}$ & $\begin{array}{l}\text { 1. Largura canina entre os pontos ao nível gengival (La.C.g). } \\
\text { 2. Largura } 1^{\circ} \text { pré-molar entre os pontos ao nível gengival } \\
\text { (La.1PM.g). } \\
\text { 3. Largura } 1^{\circ} \text { molar entre os pontos ao nível gengival (La.1M.g). } \\
\text { 4. Largura } 1^{\circ} \text { molar maxilar entre as fossas centrais (La.1M.fC). } \\
\text { 5. Comprimento } 1^{\circ} \text { molar (Co.1M). } \\
\text { 6. Comprimento do arco basal (CoB.1M). } \\
\text { 7. Largura basal (LaB.1PM). }\end{array}$ \\
\hline 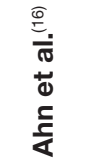 & $\begin{array}{l}\text { 1. Largura intercanino: distância entre as cúspides das coroas } \\
\text { dos caninos decíduos ou permanentes. }\end{array}$ & $\begin{array}{l}\text { 1. Largura canina maxilar entre as cúspides dos caninos } \\
\text { decíduos (La.c.cus). } \\
\text { 2. Largura canina maxilar entre as cúspides dos caninos } \\
\text { permanentes (La.C.cus). }\end{array}$ \\
\hline $\begin{array}{l}\frac{E}{E} \\
\frac{1}{0} \\
\frac{1}{0} \\
\frac{0}{0} \\
\frac{0}{0}\end{array}$ & $\begin{array}{l}\text { 1. Largura interpremolar: distância entre os sulcos centrais dos } \\
1^{\text {os }} \text { pré-molares. } \\
\text { 2. Largura intermolar: distância entre as fossas centrais dos } 1^{\text {os }} \\
\text { molares. }\end{array}$ & $\begin{array}{l}\text { 1. Largura } 1^{\circ} \text { pré-molar maxilar entre os sulcos centrais (La.1PM.sc). } \\
\text { 2. Largura } 1^{\circ} \text { molar maxilar entre as fossas centrais (La.1M.fC). }\end{array}$ \\
\hline 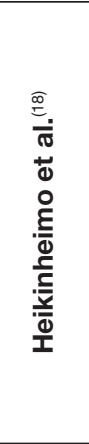 & $\begin{array}{l}\text { 1. Largura intercanina: } \\
\text { a) distância entre as cúspides dos caninos; } \\
\text { b) distância entre os caninos medidas através da interseção da } \\
\text { margem gengival com o longo eixo do dente. } \\
\text { 2. Largura Interbicúspide } 1^{\circ} \text { pré-molar: distância entre as } \\
\text { cúspides linguais dos } 1^{\text {os }} \text { pré-molares; } \\
\text { 3. Largura Interbicúspide } 2^{\circ} \text { pré-molar: distância entre as } \\
\text { cúspides linguais dos } 2^{\circ \text { os }} \text { pré-molares. } \\
\text { 4. Largura Intermolar: } \\
\text { a) distância entre as cúspides mesiolinguais; } \\
\text { b) distância entre a cúspide distolinguais; } \\
\text { c) distância da margem gengival ao nível das cúspides } \\
\text { mesiolinguais. }\end{array}$ & $\begin{array}{l}\text { 1. Largura canina maxilar: } \\
\text { a) entre as cúspides (La.C.cus). } \\
\text { b) ao nível gengival (La.C.g). } \\
\text { 2. Largura } 1^{\circ} \text { pré-molar maxilar entre as cúspides palatinas } \\
\text { (La.1PM.cp). } \\
\text { 3. Largura } 2^{\circ} \text { pré-molar maxilar entre as cúspides palatinas } \\
\text { (La.2PM.cp). } \\
\text { 4. Largura } 1^{\circ} \text { molar maxilar (La.1M): } \\
\text { a) entre as cúspides mesiopalatinas (La.1M.cmp); } \\
\text { b) entre as cúspides distopalatinas (La.1M.cdp); } \\
\text { c) entre os pontos ao nível gengival (La.1M.g). }\end{array}$ \\
\hline 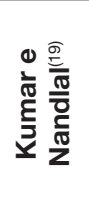 & $\begin{array}{l}\text { 1. Largura intermolar: máxima distância retilínea entre as pontas } \\
\text { das cúspides mesiovestibulares dos } 1^{\text {os }} \text { molares. } \\
\text { 2. Comprimento do arco maxilar: distância da linha que conecta } \\
\text { os } 1^{\text {os }} \text { molares até superfície labial dos incisivos centrais. } \\
\text { 3. Profundidade do palato: da linha correspondente à distância } \\
\text { intermolar até o palato. }\end{array}$ & $\begin{array}{l}\text { 1. Largura } 1^{\circ} \text { molar maxilar entre as cúspides mesiovestibulares } \\
\text { (La.1M.cmv). } \\
\text { 2. Comprimento } 1^{\circ} \text { molar (Co.1M). } \\
\text { 3. Profundidade } 1^{\circ} \text { molar maxilar (Pr.1M). }\end{array}$ \\
\hline
\end{tabular}


Quadro 1. Continuação...

\begin{tabular}{|c|c|c|}
\hline $\begin{array}{l}\text { Autor } \\
\text { ano }\end{array}$ & $\begin{array}{l}\text { Descrição das mensurações realizadas no arco dentário } \\
\text { maxilar conforme os artigos selecionados }\end{array}$ & $\begin{array}{l}\text { Nomenclatura padronizada e abreviações } \\
\text { utilizadas nesta Revisão }\end{array}$ \\
\hline 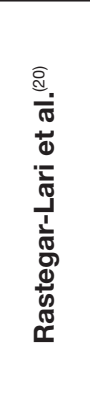 & $\begin{array}{l}\text { 1. Largura entre os caninos: distância entre as cúspides dos } \\
\text { caninos. } \\
\text { 2. Largura entre os } 1^{\text {os }} \text { pré-molares: distância entre o término } \\
\text { distal do sulco dos } 1^{\text {os }} \text { pré-molares. } \\
\text { 3. Largura entre os } 1^{\text {os }} \text { molares: } \\
\text { a) distância entre as cúspides mesiovestibulares dos } 1^{\text {os }} \text { molares; } \\
\text { b) distância entre as fossas centrais oclusais dos } 1^{\text {os }} \text { molares; } \\
\text { c) distância entre o ponto médio das faces linguais dos } 1^{\text {os }} \\
\text { molares. } \\
\text { 4. Comprimento do arco: do ponto de contato entre os incisivos } \\
\text { centrais até a linha que conecta o ponto mesial dos } 1^{\text {os }} \text { pré- } \\
\text { molares. }\end{array}$ & $\begin{array}{l}\text { 1. Largura canina maxilar entre as cúspides (La.C.cus). } \\
\text { 2. Largura } 1^{\circ} \text { pré-molar maxilar entre os sulcos distais (La.1PM. } \\
\text { sd). } \\
\text { 3. Largura } 1^{\circ} \text { molar maxilar (La.1M): } \\
\text { a) entre as cúspides mesiovestibulares (La.1M.cmv); } \\
\text { b) entre as fossas centrais (La.1M.fC); } \\
\text { c) ao nível gengival (La.1M.g). } \\
\text { 4. Comprimento } 1^{\circ} \text { pré-molar maxilar (Co.1PM). }\end{array}$ \\
\hline 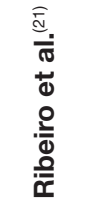 & $\begin{array}{l}\text { 1. Largura intercanina: distância entre as cúspides dos caninos. } \\
\text { 2. Largura intermolar: distância entre o ponto médio das } \\
\text { cúspides mesiopalatais, disto-palatais, mesiovestibulares e } \\
\text { distovestibulares. }\end{array}$ & $\begin{array}{l}\text { 1. Largura canina maxilar entre as cúspides (La.C.cus). } \\
\text { 2. Largura } 1^{\circ} \text { molar maxilar entre as fossas centrais (La.1M.fc). }\end{array}$ \\
\hline 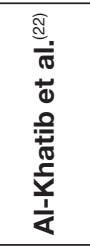 & $\begin{array}{l}\text { 1. Distância intercanina: distância entre as cúspides dos caninos. } \\
\text { 2. Distância inter } 1^{\circ} \text { pré-molar: distância entre as cúspides } \\
\text { vestibulares dos } 1^{\text {os }} \text { pré-molares. } \\
\text { 3. Distância inter } 2^{\circ} \text { pré-molar: distância entre as cúspides } \\
\text { vestibulares dos } 2^{\text {os }} \text { pré-molares. } \\
\text { 4. Distância intermolar: distância entre as cúspides } \\
\text { mesiovestibulares dos } 1^{\text {os }} \text { molares. }\end{array}$ & $\begin{array}{l}\text { 1. Largura canina maxilar entre as cúspides (La.C.cus). } \\
\text { 2. Largura } 1^{\circ} \text { pré-molar maxilar entre as cúspides vestibulares } \\
\text { (La.1PM.cv). } \\
\text { 3. Largura } 2^{\circ} \text { pré-molar maxilar entre as cúspides vestibulares } \\
\text { (La.2PM.cv). } \\
\text { 4. Largura } 1^{\circ} \text { molar maxilar entre as cúspides mesiovestibulares } \\
\text { (La.1M.cmv). }\end{array}$ \\
\hline 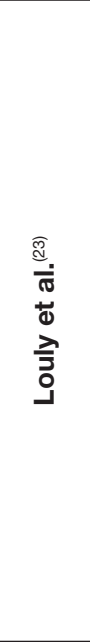 & $\begin{array}{l}\text { 1. Largura intercanina: distância entre as cúspides dos caninos. } \\
\text { 2. Largura inter } 1^{\circ} \text { pré-molar: distância entre os sulcos centrais } \\
\text { dos } 1^{\text {os }} \text { pré-molares. } \\
\text { 3. Largura inter } 1^{\circ} \text { molar: distância entre os sulcos centrais dos } \\
1^{\text {os }} \text { molares. } \\
\text { 4. Largura inter } 2^{\circ} \text { molar: distância entre os sulcos centrais dos } \\
2^{\text {os }} \text { molares. } \\
\text { 5. Profundidade maxilar: da linha que conecta o plano oclusal até } \\
\text { a maior profundidade do palato. } \\
\text { 6. Comprimento total do arco: distância perpendicular a partir } \\
\text { da linha que une os incisivos centrais e o ponto superior da rafe } \\
\text { palatina até a linha que mede a profundidade ao nível dos } 1^{\text {os }} \\
\text { molares. } \\
\text { 7. Comprimento do seguimento anterior do arco: distância } \\
\text { perpendicular da linha que conecta os incisivos centrais até a } \\
\text { linha que conecta as distais dos caninos. } \\
\text { 8. Comprimento do seguimento posterior do arco: diferença } \\
\text { entre o comprimento total da arcada e o comprimento do } \\
\text { segmento anterior. }\end{array}$ & $\begin{array}{l}\text { 1. Largura canina maxilar entre as cúspides (La.C.cus). } \\
\text { 2. Largura } 1^{\circ} \text { pré-molar maxilar entre os sulcos centrais (La.1PM. } \\
\text { sc). } \\
\text { 3. Largura } 1^{\circ} \text { molar maxilar entre as fossas centrais (La.1M.fC). } \\
\text { 4. Largura } 2^{\circ} \text { molar maxilar entre as fossas centrais (La.2M.fC). } \\
\text { 5. Profundidade maxilar máxima ao nível do plano oclusal (Pr. } \\
\text { Max.o). } \\
\text { 6. Comprimento } 1^{\circ} \text { molar maxilar (Co.1M). } \\
\text { 7. Comprimento canino maxilar (Co.C). } \\
\text { 8. Diferença entre o comprimento } 1^{\circ} \text { molar maxilar e o } \\
\text { comprimento canino maxilar (Co.1M-Co.C). }\end{array}$ \\
\hline 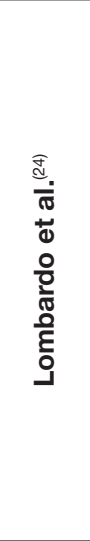 & $\begin{array}{l}\text { 1. Diâmetro intercanino: distância entre os pontos mais } \\
\text { proeminentes no eixo central da superfície lingual da coroa dos } \\
\text { caninos. } \\
\text { 2. Diâmetro intermolar ao nível dos } 1^{\text {os }} \text { molares: distância entre os } \\
\text { pontos mais proeminentes da superfície lingual dos } 1^{\text {os }} \text { molares } \\
\text { no centro da coroa clínica. } \\
\text { 3. Diâmetro intermolar ao nível dos } 2^{\circ s} \text { molares: distância entre os } \\
\text { pontos mais proeminentes da superfície lingual dos } 2^{\circ s} \text { molares } \\
\text { no centro da coroa clínica. } \\
\text { 4. Profundidade canina: é a distância do ponto entre os incisivos } \\
\text { centrais e a linha que conecta os pontos mais proeminentes no } \\
\text { eixo central da superfície lingual da coroa dos caninos. } \\
5 \text {. Profundidade } 1^{\circ} \text { molar: é a distância do ponto entre os } \\
\text { incisivos centrais e a linha que conecta os } 1^{\circ s} \text { molares. } \\
6 \text {. Profundidade } 2^{\circ} \text { molar: é a distância do ponto entre os } \\
\text { incisivos centrais e a linha que conecta os } 2^{\circ s} \text { molares. }\end{array}$ & $\begin{array}{l}\text { 1. Largura canina entre os pontos ao nível gengival (La.C.g). } \\
\text { 2. Largura } 1^{\circ} \text { molar entre os pontos ao nível gengival (La.1M.g). } \\
\text { 3. Largura } 2^{\circ} \text { molar entre os pontos ao nível gengival (La.2M.g). } \\
\text { 4. Comprimento canino gengival (Co.C.g). } \\
\text { 5. Comprimento } 1^{\circ} \text { molar gengival (Co.1M.g). } \\
\text { 6. Comprimento } 2^{\circ} \text { molar gengival (Co.2M.g). }\end{array}$ \\
\hline
\end{tabular}


Quadro 1. Continuação...

\begin{tabular}{|c|c|c|}
\hline $\begin{array}{l}\text { Autor } \\
\text { ano }\end{array}$ & $\begin{array}{l}\text { Descrição das mensurações realizadas no arco dentário } \\
\text { maxilar conforme os artigos selecionados }\end{array}$ & $\begin{array}{c}\text { Nomenclatura padronizada e abreviações } \\
\text { utilizadas nesta Revisão }\end{array}$ \\
\hline $\begin{array}{l}\frac{\sqrt{0}}{\frac{\pi}{\sigma}} \\
\frac{\pi}{\sigma} \\
\frac{\pi}{\sigma}\end{array}$ & $\begin{array}{l}\text { 1. Largura canina: distância entre os pontos clínicos dos } \\
\text { braquetes dos caninos. } \\
\text { 2. Largura intermolar: distância entre os pontos clínicos dos } \\
\text { braquetes dos } 1^{\text {os }} \text { molares. } \\
\text { 3. Profundidade canina: distância desde a linha que conecta os } \\
\text { pontos clínicos do braquetes dos caninos até o ponto entre os } \\
\text { incisivos centrais. } \\
\text { 4. Profundidade molar: distância desde a linha que conecta os } \\
\text { pontos clínicos do braquetes dos } 1^{\text {os }} \text { molares até o ponto entre } \\
\text { os incisivos centrais. }\end{array}$ & $\begin{array}{l}\text { 1.Largura canina maxilar entre as vestibulares (La.C.v). } \\
\text { 2. Largura } 1^{\circ} \text { molar maxilar entre as vestibulares (La.1M.v). } \\
\text { 3. Comprimento canino maxilar (Co.C). } \\
\text { 4. Comprimento } 1^{\circ} \text { molar maxilar (Co.1M). }\end{array}$ \\
\hline $\begin{array}{l}\bar{d} \\
\frac{0}{\pi} \\
\frac{0}{0} \\
\frac{5}{\sigma} \\
\frac{\pi}{0} \\
\frac{0}{\alpha}\end{array}$ & $\begin{array}{l}\text { 1. Largura canina maxilar: distância entre as cúspides dos } \\
\text { caninos. } \\
\text { 2. Largura pré-molar maxilar: distância entre os sulcos centrais } \\
\text { dos } 1^{\text {os }} \text { pré-molares. } \\
\text { 3. Largura molar maxilar: distância entre os pontos das fossas } \\
\text { centrais dos } 1^{\text {os }} \text { molares. } \\
\text { 4. Profundidade do arco maxilar: distância perpendicular desde a } \\
\text { superfície labial dos incisivos centrais até a linha entre as fossas } \\
\text { centrais dos } 1^{\text {os }} \text { molares. }\end{array}$ & $\begin{array}{l}\text { 1. Largura canina maxilar entre as cúspides (La.C.cus). } \\
\text { 2. Largura } 1^{\circ} \text { pré-molar entre os sulcos centrais (La.1PM.sc). } \\
\text { 3. Largura } 1^{\circ} \text { molar maxilar entre as fossas centrais (La.1M.fC). } \\
\text { 4. Comprimento } 1^{\circ} \text { molar maxilar (Co.1M). }\end{array}$ \\
\hline 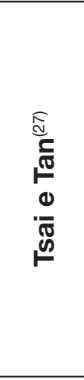 & $\begin{array}{l}\text { 1. Largura palatal do lado direito: distância entre o ponto cervical } \\
\text { do } 2^{\circ} \text { molar decíduo direito ao ponto da linha perpendicular na } \\
\text { rafe palatina. } \\
\text { 2. Largura palatal do lado esquerdo: distância entre o ponto } \\
\text { cervical do } 2^{\circ} \text { molar decíduo esquerdo ao ponto da linha } \\
\text { perpendicular na rafe palatina. } \\
\text { 3. Profundidade do palato: distância entre o ponto da rafe } \\
\text { palatina até a linha que conecta os } 2^{\circ s} \text { molares decíduos ao nível } \\
\text { gengival. } \\
\text { 4. Largura do arco dental. Distância entre as cúspides } \\
\text { mesiopalatinas dos } 2^{\circ s} \text { molares decíduos superiores. }\end{array}$ & $\begin{array}{l}\text { 1. Largura } 2^{\circ} \text { molar decíduo do ponto ao nível gengival do lado } \\
\text { direito (La. } 2 \mathrm{~m} . \mathrm{g} . \mathrm{D}) \\
\text { 2. Largura } 2^{\circ} \text { molar decíduo do ponto ao nível gengival do lado } \\
\text { esquerdo (La. } 2 \mathrm{~m} \text {.g.E) } \\
\text { 3. Profundidade palatina gengival (Pro. } 2 \mathrm{~m} . \mathrm{g}) \text {. } \\
\text { 4. Largura } 2^{\circ} \text { molar decíduo entre as cúspides mesiopalatinas } \\
(\text { La. } 2 \mathrm{~m} . \mathrm{cmp}) \text {. }\end{array}$ \\
\hline 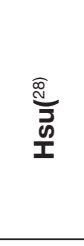 & $\begin{array}{l}\text { 1. Largura intermolar superior: distância entre as fossas centrais } \\
\text { dos } 1^{\text {os }} \text { molares superiores. } \\
\text { 2. Largura inter pré-molar superior: distância entre os sulcos } \\
\text { distais dos } 1^{\text {os }} \text { pré-molares superiores. } \\
\text { 3. Profundidade do palato: distância da parte mais profunda do } \\
\text { palato até a linha que conecta as fossas centrais dos } 1^{\text {os }} \text { molares } \\
\text { superiores. }\end{array}$ & $\begin{array}{l}\text { 1. Largura } 1^{\circ} \text { molar maxilar entre as fossas centrais (La.1M.fC). } \\
\text { 2. Largura } 1^{\circ} \text { pré-molar maxilar entre os sulcos distrais (La.1PM. } \\
\text { sd). } \\
\text { 3. Profundidade } 1^{\circ} \text { molar maxilar (Pr.1M). }\end{array}$ \\
\hline $\begin{array}{l}\text { ब. } \\
\frac{0}{\pi} \\
\frac{0}{0} \\
\frac{\pi}{0} \\
\frac{0}{0} \\
\frac{0}{0} \\
\frac{0}{0}\end{array}$ & $\begin{array}{l}\text { 6 semanas a } 2 \text { anos } \\
\text { 1. Largura do arco maxilar anterior: distância entre os pontos dos } \\
\text { sulcos laterais ao nível da crista alveolar. } \\
\text { 2. Largura do arco maxilar posterior: distância entre os pontos da } \\
\text { margem posterior da gengiva ao nível da crista alveolar. } \\
3 \text { a } 45 \text { anos } \\
\text { 1. Largura intercanina: distância entre as pontas das cúspides } \\
\text { dos caninos. } \\
\text { 2. Largura intermolar decíduo: distância entre as pontas das } \\
\text { cúspides mesiovestibulares dos } 2^{\text {os }} \text { molares decíduos ( } 3 \text { a } 5 \\
\text { anos). } \\
\text { 3. Largura intermolar permanente: distância entre as pontas das } \\
\text { cúspides mesiovestibulares dos } 1^{\text {os }} \text { molares permanentes para } \\
\text { todas as idades subsequentes. }\end{array}$ & $\begin{array}{l}\text { 1.Largura maxilar anterior entre os pontos ao nível gengival (La. } \\
\text { anterior.g). } \\
\text { 2. Largura maxilar posterior entre os pontos ao nível gengival (La. } \\
\text { posterior.g) } \\
\text { 1. Largura canina maxilar entre as cúspides (La.C.cus). } \\
\text { 2. Largura } 2^{\circ} \text { molar decíduo entre as cúspides mesiovestibulares } \\
\text { (La.2m.cmv). } \\
\text { 3. Largura } 1^{\circ} \text { molar permanente entre as cúspides } \\
\text { mesiovestibulares (La.1M.cmv). }\end{array}$ \\
\hline
\end{tabular}

18 estudos. Verificou-se que cinco estudos denominaram as medidas do plano sagital do arco como profundidade ${ }^{(12,13,24-26)}$, enquanto outros quatro as denominam de comprimento ${ }^{(15,19,20,23)}$. Já em quatro estudos a medida denominada de 'profundidade' se relacionou ao plano vertical ${ }^{(19,23,27,28)}$. Em vista disso, optou-se por padronizar as medidas do plano sagital como 'comprimento' e as do plano vertical como 'profundidade'. As medidas do plano transversal foram denominadas de 'largura' (Quadro 1).

Todos os estudos incluídos realizaram as medidas tendo por base os modelos de gesso do arco dental maxilar. As medidas foram realizadas diretamente nos modelos com paquímetro digital ou analógico ${ }^{(14,15,17-19,20,23,26,29)}$, paquímetro analógico com acessório para medir a altura palatina ${ }^{(19)}$ ou com compasso tridimensional de Korkhaus $^{(23)}$; em modelos digitalizados, em fotos e copiadoras, sendo mensurados a partir de softwares ${ }^{(12-14,16,21,22,24,25,27)}$; e em cópias impressas dos modelos com mensurações realizadas com paquímetro digital ${ }^{(28)}$.

Quanto aos pontos de referência utilizados na obtenção das medidas, a maioria utilizou algum ponto anatômico do dente (dimensões do arco dentário maxilar) e apenas seis 
estudos $^{(15,18,20,24,27,29)}$ realizaram pelo menos uma medida tendo por base algum ponto no rebordo gengival, o que possibilitou a obtenção das dimensões do palato duro. Todos os estudos consideraram o plano transversal na realização das medidas, nove também realizaram medidas no plano sagital ${ }^{(12,13,15,19,20,23-26)}$ e quatro no plano vertical ${ }^{(19,23,27,28)}$.

\section{Análise das dimensões do palato duro ou do arco dentário maxilar de acordo com o gênero e a idade}

Os 18 estudos incluídos nesta revisão, foram publicados entre 1997 e 2016. Treze apresentaram delineamento transversal $^{(12-15,17,19,20,22-25,27,28)}$ e cinco, longitudinal ${ }^{(16,18,21,26,29)}$. Destes, 11 apresentaram as dimensões do palato duro ou do arco dentário maxilar conforme o gênero ${ }^{(12-15,17,20,24-28)}$, seis conforme idade e gênero ${ }^{(16,18,19,22,23,29)}$ e somente um estudo apresentou as dimensões do palato duro conforme a faixa etária(21) (Tabela 2).

Algumas constatações puderam ser realizadas ao analisar as informações destinadas à comparação das dimensões do palato duro e do arco dentário maxilar com relação ao gênero (Tabela 2). Um estudo realizou a comparação entre gênero na fase de dentição decídua (crianças de 4 a 5 anos) ${ }^{(27)}$ e verificou que os meninos chineses apresentaram maior largura maxilar, bem como largura maxilar direita e esquerda ao nível dos segundos molares decíduos maiores do que as meninas, não sendo verificada diferença na profundidade do palato duro.

Outra pesquisa foi realizada com uma amostra que apresenta média de idade nove anos para ambos os gêneros ${ }^{(26)}$, sendo evidenciada largura maxilar significativamente maior nos meninos ao nível dos primeiros pré-molares e molares, não sendo observada diferença entre o gênero na largura maxilar entre os caninos e no comprimento maxilar anteroposterior até os primeiros molares. No período de dentição mista, um dos estudos encontrou palato duro significativamente maior nos meninos somente aos dez anos ${ }^{(23)}$.

Ao analisar o conjunto dos estudos descritos na Tabela 2, verificou-se que praticamente todas as médias das medidas realizadas no plano transversal (largura), independentemente do ponto de referência utilizado, foram maiores no gênero masculino. Quanto aos estudos que realizaram análise estatística para comparação dos valores relacionados ao plano transversal (largura) entre gênero na fase de dentição permanente, verificou-se que cinco $^{(13-15,22,29)}$ encontraram diferença significativa entre gênero, enquanto outros quatro ${ }^{(12,17,20,24)}$ não evidenciaram diferença.

Das doze pesquisas realizadas com sujeitos em fase de dentição permanente abordando comparação entre gênero ${ }^{(12-15,17,18,20,22,24,25,28,29)}$, seis realizaram pelo menos uma medida do arco dentário maxilar no plano sagital (comprimento) ${ }^{(12,13,15,20,24,25)}$. Destes, cinco compararam a diferença no comprimento maxilar entre gênero ${ }^{(12,13,15,20,24)}$.

Em relação aos resultados encontrados nestes cinco trabalhos, Hasegawa et al. ${ }^{(15)}$ verificaram comprimento basal do palato duro até o nível dos primeiros molares significativamente maior em mulheres mongolianas e comprimento anteroposterior maxilar significativamente maior nos japoneses do gênero masculino. Dois estudos evidenciaram comprimento maxilar significativamente maior no gênero masculino ${ }^{(13,20)}$, enquanto outros dois $^{(12,24)}$ não encontraram diferença.

Nas aferições do plano vertical (profundidade) na fase de dentição permanente, apenas uma pesquisa realizou a medida da profundidade maxilar ao nível dos primeiros molares, sendo as médias muito semelhantes entre os gêneros ${ }^{(28)}$.

Com relação às dimensões do palato duro ou do arco dentário maxilar de acordo com as idades, pôde-se verificar que a maioria dos estudos realizou apenas análise descritiva dos resultados ${ }^{(18,19,22)}$ ou estatística analítica para comparação entre os gêneros nas diferentes idades ${ }^{(16,23)}$. A comparação estatística entre as medidas nas diferentes idades foi considerada apenas em dois trabalhos ${ }^{(21,29)}$.

No estudo longitudinal de Ribeiro et al. ${ }^{(21)}$, verificou-se que as larguras do arco dentário maxilar entre os caninos e primeiros molares na faixa etária de 10 a 14 anos foram significativamente maiores em relação às crianças de seis a oito anos. A diferença entre os dois períodos foi igual a 3,21 $\mathrm{mm}$ na largura entre os caninos e de 2,16 mm na largura entre os primeiros molares ${ }^{(21)}$.

Por fim, Bishara et al. ${ }^{(29)}$ avaliaram longitudinalmente sujeitos do nascimento até os 45 anos de idade através de medidas no plano transversal (largura). Pôde-se observar que, das seis semanas de vida até os dois anos, ou seja, período dos roletes gengivais até a dentição decídua, houve um aumento de 4,2 $\mathrm{mm}$ na média da largura anterior do palato duro nos meninos e de 4,0 mm nas meninas, bem como um aumento de 5,3 $\mathrm{mm}$ na largura posterior do palato duro dos meninos e de 3,9 mm no das meninas. Dos três anos até os 13 anos, a largura do arco maxilar anterior e posterior aumentaram gradativamente, inclusive com significância estatística entre as idades. Dos três aos cinco anos, a média da largura entre os caninos aumentou 1,5 mm nos meninos e 1,0 nas meninas e, dos oito aos 13 anos, aumentou 2,6 $\mathrm{mm}$ e 2,4 $\mathrm{mm}$ nos meninos e meninas, respectivamente. Já a média da largura entre os segundos molares decíduos dos três aos cinco anos aumentou 2,6 mm nos meninos e 1,5 mm nas meninas. Por sua vez, a média entre os primeiros molares permanentes aumentou 2,4 $\mathrm{mm}$ dos oito aos 13 anos nos meninos e 2,0 mm nas meninas. Também foi possível observar que no gênero feminino, dos 26 para os 45 anos, houve um decréscimo na largura entre os caninos e, dos 13 para os 26 anos, na largura entre os primeiros molares. Neste estudo, todas as médias das medidas realizadas nas diferentes idades estudadas foram significativamente maiores no gênero masculino ${ }^{(29)}$.

\section{Avaliação da qualidade e do risco de viés}

A pontuação referente à análise da qualidade interna e controle de viés realizada por meio da escala "Newcastle Ottawa Quality" (Tabela 3) variou entre três e cinco para os estudos com delineamento transversal (máximo 10 pontos) e entre quatro e cinco nos estudos com delineamento longitudinal (máximo 9 pontos). Considerando que uma maior pontuação representa melhor qualidade e menor risco de viés, os estudos analisados nesta revisão sistemática mostraram-se com qualidade de baixa a intermediária. 
Tabela 3. Qualidade interna e controle do risco de viés conforme Escala "Newcastle - Ottawa Quality"

\begin{tabular}{|c|c|c|c|c|c|}
\hline Autor & Desenho & Seleção & Comparabilidade & Resultado & Total \\
\hline Mina et al. ${ }^{(12)}$ & Transversal & $\star \star$ & $\star$ & $\star$ & $4(10)$ \\
\hline Patel e Daruwala ${ }^{(13)}$ & Transversal & $\star$ & $\star$ & $\star$ & $3(10)$ \\
\hline Shahid et al. ${ }^{(14)}$ & Transversal & $\star \star$ & $\star$ & $\star$ & $4(10)$ \\
\hline Hasegawa et al. ${ }^{(15)}$ & Transversal & $\star \star \star$ & $\star$ & $\star$ & $5(10)$ \\
\hline Ahn et al. ${ }^{(16)}$ & Longitudinal & $\star \star$ & $\star$ & $\star \star$ & $5(9)$ \\
\hline Celebi et al. ${ }^{(17)}$ & Transversal & $\star \star \star$ & $\star$ & $\star$ & $5(10)$ \\
\hline Heikinheimo et al. ${ }^{(18)}$ & Longitudinal & $\star \star \star$ & $\star$ & $\star$ & $5(9)$ \\
\hline Kumar e Nandlal ${ }^{(19)}$ & Transversal & $\star$ & $\star \star$ & $\star$ & $4(10)$ \\
\hline Rastegar-Lari et al. ${ }^{(20)}$ & Transversal & $\star \star \star$ & $\star$ & $\star$ & $5(10)$ \\
\hline Ribeiro et al. ${ }^{(21)}$ & Longitudinal & $\star \star$ & $\star$ & $\star$ & $4(9)$ \\
\hline Al-Khatib et al. ${ }^{(22)}$ & Transversal & $\star \star \star$ & $\star$ & $\star$ & $5(10)$ \\
\hline Louly et al. ${ }^{(23)}$ & Transversal & $\star \star \star$ & $\star$ & $\star$ & $5(10)$ \\
\hline Lombardo et al. ${ }^{(24)}$ & Transversal & $\star \star$ & $\star$ & $\star$ & $4(10)$ \\
\hline Slaj et al. ${ }^{(25)}$ & Transversal & $\star$ & $\star$ & $\star$ & $3(10)$ \\
\hline Arslan et al. ${ }^{(26)}$ & Longitudinal & $\star \star$ & $\star$ & $\star$ & $4(9)$ \\
\hline Tsai e $\operatorname{Tan}^{(27)}$ & Transversal & $\star$ & $\star$ & $\star$ & $3(10)$ \\
\hline $\mathrm{Hsu}^{(28)}$ & Transversal & $\star$ & $\star$ & $\star$ & $3(10)$ \\
\hline Bishara et al. ${ }^{(29)}$ & Longitudinal & $\star \star$ & $\star \star$ & $\star$ & $5(9)$ \\
\hline
\end{tabular}

Legenda: $\star=$ um ponto; $\star \star \quad$ =dois pontos; $\star \star \star$ três pontos

\section{CONCLUSÃO}

As médias das aferições da largura do palato duro e do arco dentário maxilar foram maiores no gênero masculino na maioria dos estudos, sendo que a maioria dos artigos selecionados encontraram alguma diferença significativa entre os gêneros.

Nos estudos que verificaram a influência da idade nas dimensões do palato duro ou do arco dentário maxilar, observou-se que dois apresentaram diferença estatística entre as medidas realizadas de acordo com as idades ou faixas etárias, sugerindo influência da idade sobre as dimensões transversais do arco dentário maxilar.

Analisando conjuntamente os resultados, pôde-se verificar, como esperado, que as médias dos valores de referência encontrados aumentaram gradativamente desde o nascimento até aproximadamente as idades entre 12 e 15 anos, período correspondente à dentição permanente. Observou-se que existem alguns valores de referência, expressos em média, oriundos de amostras de conveniência, o que limita a extrapolação destes resultados para outras populações. Além disso, predominam valores relacionados às mensurações no plano transversal, carecendo de valores relacionados ao plano vertical e sagital.

Constatou-se que todos os estudos tiveram por base modelos de gesso, sendo as medidas realizadas diretamente nos modelos, em modelos digitalizados ou em imagens impressas. Os instrumentos utilizados para obtenção das medidas foram paquímetros, compasso tridimensional e softwares.

Os parâmetros de referências encontrados para análise quantitativa do palato duro segundo gênero e idade, especialmente na população brasileira, ainda são escassos. Além disso, há carência de estudos que consideram pontos de referência tendo por base o rebordo gengival, bem como o plano vertical e sagital para obtenção das medidas do palato duro. Com isso, há necessidade de estudos adicionais que abordem avaliação quantitativa do palato duro segundo o gênero e idade em amostras representativas da população brasileira para que o uso da avalição quantitativa do palato duro como coadjuvante da avaliação antroposcópica seja factível na prática clínica.

\section{REFERÊNCIAS}

1. Felício CM, Folha GA, Ferreira CL, Medeiros AP. Expanded protocol of orofacial myofunctional evaluation with scores: validity and reliability. Int J Pediatr Otorhinolaryngol. 2010;74(11):1230-9. http://dx.doi.org/10.1016/j. ijporl.2010.07.021. PMid:20800294.

2. Marchesan IQ, Berretin-Félix G, Genaro KF. MBGR protocol of orofacial myofunctional evaluation with scores. Int J Orofacial Myology. 2012;38:3877. PMid:23362752.

3. Maria CM. Silva AMTd, Busanello-Stella AR, Bolzan GdP, Berwig LC Avaliação da profundidade do palato duro: correlação entre o método quantitativo e qualitativo. Rev CEFAC. 2013;15(5):1292-9. http://dx.doi. org/10.1590/S1516-18462013005000029.

4. Freitas F, Bastos E, Primo L, Freitas V. Evaluation of the palate dimensions of patients with perennial allergic rhinitis. Int J Paediatr Dent. 2001;11(5):36571. http://dx.doi.org/10.1046/j.0960-7439.2001.00292.x. PMid:11572268.

5. Ghasempour M, Mohammadzadeh I, Garakani S. Palatal arch diameters of patients with allergic rhinitis. Iran J Allergy Asthma Immunol. 2009;8(1):634. PMid:19279362.

6. Berwig LC, Silva AM, Côrrea EC, Moraes AB, Montenegro MM, Ritzel RA. Hard palate dimensions in nasal and mouth breathers from differen etiologies. J Soc Bras Fonoaudiol. 2011;23(4):308-14. http://dx.doi. org/10.1590/S2179-64912011000400004. PMid:22231050.

7. Berwig LC, Montenegro MM, Ritzel RA, Silva AMT, Corrêa ECR, Mezzomo CL. Influence of the respiratory mode and nonnutritive sucking habits in the palate dimensions. Braz J Oral Sci. 2011;10(1):42-9.

8. Berwig LC, Silva AMT, Côrrea ECR, Moraes AB, Montenegro MM, Ritzel RA. Análise quantitativa do palato duro em diferentes tipologias faciais de respiradores nasais e orais. Rev CEFAC. 2012;14(4):616-25. http://dx.doi.org/10.1590/S1516-18462011005000134.

9. Costa TLS, Silva HJ, Cunha DA. Análise qualitativa inter-observadores e avaliação morfométrica do palato duro. Rev CEFAC. 2005;7(3):326-35.

10. Wells G, Shea B, O’Connell D, Peterson J, Welch V, Losos M, et al. The Newcastle-Ottawa Scale (NOS) for assessing the quality of nonrandomised studies in meta analyses [Internet]. Ottawa: University of Ottawa, 2001 
[citado em 2006 Nov 2]. Disponível em: http://www.ohri.ca/programs/ clinical_epidemiology/oxford.htm

11. Herzog R, Álvarez-Pasquin MJ, Díaz C, Del Barrio JL, Estrada JM, Gil Á. Are healthcare workers' intentions to vaccinate related to their knowledge, beliefs and attitudes? A systematic review. BMC Public Health. 2013;13(1):154. http://dx.doi.org/10.1186/1471-2458-13-154. PMid:23421987.

12. Mina M, Borzabadi-Farahani A, Tehranchi A, Nouri M, Younessian F. Mathematical beta function formulation for maxillary arch form prediction in normal occlusion population. Odontology. 2016;105(2):229-36. http:// dx.doi.org/10.1007/s10266-016-0244-7. PMid:27167385.

13. Patel MN, Daruwala NR. Appraisal of dental arch dimension in Gujarati males and females. Adv Hum Biol. 2015;5(3):61-7.

14. Shahid F, Alam MK, Khamis MF, Honda Y, Sugita Y, Maeda H. Geomorphometrics of tooth size and arch dimension analysis by conventional digital caliper and digital stereomicroscope to establish standard norms for the pakistani population. J Hard Tissue Biol. 2015;24(2):155-68. http:// dx.doi.org/10.2485/jhtb.24.155.

15. Hasegawa Y, Amarsaikhan B, Chinvipas N, Tsukada SI, Terada K, Uzuka $\mathrm{S}$, et al. Comparison of mesiodistal tooth crown diameters and arch dimensions between modern Mongolians and Japanese. Odontology. 2014;102(2):16775. http://dx.doi.org/10.1007/s10266-013-0130-5. PMid:24026430.

16. Ahn JS, Park MS, Cha HS, Song HC, Park YS. Three-dimensional interpretation of intercanine width change in children: a 9-year longitudinal study. Am J Orthod Dentofacial Orthop. 2012;142(3):323-32. http://dx.doi. org/10.1016/j.ajodo.2012.04.012. PMid:22920698.

17. Celebi AA, Tan E, Gelgor IE. Determination and application of Pont's Index in Turkish Population. Sci World J. 2012;2012:1-5. http://dx.doi. org/10.1100/2012/494623. PMid:22654616.

18. Heikinheimo K, Nystrom M, Heikinheimo T, Pirttiniemi P, Pirinen S. Dental arch width, overbite, and overjet in a Finnish population with normal occlusion between the ages of 7 and 32 years. Eur J Orthod. 2012;34(4):418-26. http://dx.doi.org/10.1093/ejo/cjr025. PMid:21357654.

19. Kumar SS, Nandlal B. Effects of asthma and inhalation corticosteroids on the dental arch morphology in children. J Indian Soc Pedod Prev Dent. 2012;30(3):242-9. http://dx.doi.org/10.4103/0970-4388.105018. PMid:23263429.

20. Rastegar-Lari T, Al-Azemi R, Thalib L, Artun J. Dental arch dimensions of adolescent Kuwaitis with untreated ideal occlusion: variation and validity of proposed expansion indexes. Am J Orthod Dentofacial Orthop.
2012;142(5):635-44. http://dx.doi.org/10.1016/j.ajodo.2012.05.018. PMid:23116504.

21. Ribeiro JS, Ambrosio AR, Santos-Pinto A, Shimizu IA, Shimizu RH Evaluation of transverse changes in the dental arches according to growth pattern: a longitudinal study. Dental Press J Orthod. 2012;17(1):66-73. http://dx.doi.org/10.1590/S2176-94512012000100010.

22. Al-Khatib AR, Rajion ZA, Masudi SM, Hassan R, Anderson PJ, Townsend GC. Tooth size and dental arch dimensions: a stereophotogrammetric study in Southeast Asian Malays. Orthod Craniofac Res. 2011;14(4):243-53. http://dx.doi.org/10.1111/j.1601-6343.2011.01529.x. PMid:22008304.

23. Louly F, Nouer PRA, Janson G, Pinzan A. Dental arch dimensions in the mixed dentition: a study of Brazilian children from 9 to 12 years of age. J Appl Oral Sci. 2011;19(2):169-74. http://dx.doi.org/10.1590/S167877572011000200014. PMid:21552719.

24. Lombardo L, Saba L, Scuzzo G, Takemoto K, Oteo L, Palma JC, et al. A new concept of anatomic lingual arch form. Am J Orthod Dentofacial Orthop. 2010;138(3):260.e1-13, discussion 260-1. http://dx.doi.org/10.1016/j. ajodo.2010.04.022. PMid:20816292.

25. Slaj M, Spalj S, Pavlin D, Illes D, Slaj M. Dental archforms in dentoalveolar Class I, II and III. Angle Orthod. 2010;80(5):919-24. http://dx.doi. org/10.2319/112609-672.1. PMid:20578864.

26. Arslan SG, Kama JD, Sahin S, Hamamci O. Longitudinal changes in dental arches from mixed to permanent dentition in a Turkish population. Am J Orthod Dentofacial Orthop. 2007;132(5):15-21. http://dx.doi.org/10.1016/j. ajodo.2007.06.009. PMid:18005825.

27. Tsai HH, Tan CT. Morphology of the palatal vault of primary dentition in transverse view. Angle Orthod. 2004;74(6):774-9. PMid:15673140.

28. Hsu BS. The nature of arch width difference and palatal depth of the anterior open bite. Am J Orthod Dentofacial Orthop. 1998;113(3):344-50. http:// dx.doi.org/10.1016/S0889-5406(98)70307-5. PMid:9517728.

29. Bishara SE, Jakobsen JR, Treder J, Nowak A. Arch width changes from 6 weeks to 45 years of age. Am J Orthod Dentofacial Orthop. 1997;111(4):4019. http://dx.doi.org/10.1016/S0889-5406(97)80022-4. PMid:9109585.

\section{Contribuição dos autores}

LCB foi responsável pela coleta, tabulação, análise dos dados e redação do manuscrito; MM foi responsável pela coleta, análise dos dados e redação do manuscrito; JMM e MMM foram responsáveis pela análise dos dados e redação do manuscrito; TMA e AMTS foram responsáveis pela orientação geral das etapas de execução e elaboração do manuscrito. 